\title{
Gut Microbiota in Health and Diseases - A Review
}

\author{
Poonam Jethwani $^{1 *}$ and Kiran Grover ${ }^{2}$ \\ ${ }^{1}$ Department of Life and Basic Sciences, Jaipur National University, Jaipur-302017, \\ Rajasthan, India \\ ${ }^{2}$ Department of Food and Nutrition, Punjab Agricultural University, Ludhiana-141001, \\ Punjab, India \\ *Corresponding author
}

\section{Keywords}

Gut microbiota, Dysbiosis,

Prebiotics, Probiotics, Faecal microbiota transplant

\section{Article Info}

Accepted: 12 July 2019 Available Online: 10 August 2019

\section{A B S T R A C T}

The gut micro flora plays vital role in health status of the host. Human physiology and nutrition are greatly affected by the majority of microbes living in the gut. The most dominant phyla, making up to 90 percent of the total microbial population in humans are Bacteroidetes and Firmicutes followed by Actinobacteria Proteobacteria, Tenericutes, and Verrucomicrobia. The multiplication and establishment of gut microbiome begins at birth, but the alteration in composition of the microbial community depends upon various factors such as the age, gender, genetic composition, geographic location, environmental factors, diet and health status of an individual. Therefore it is of prior importance to study and understand the composition of gut microbiome of different ethnic groups. The gut flora has a major role in maintaining the homeostasis by controlling nutrient metabolism, metabolic pathways, synthesis and excretion of vitamins, preventing colonization by pathogens, maintenance of intestinal epithelial barrier function and development of systematic and mucosal immune response. It has been suggested that decrease in density, diversity and activity of gut microbiota (or dysbiosis) can lead to many diseases such as obesity and metabolic syndrome, cancer promotion, inflammatory bowel disease (IBD), encompassing ulcerative colitis (UC) and Crohn's disease (CD), irritable bowel syndrome such as constipation, diarrhoea and bloating. The latest researches has revealed new candidate organisms among healthy gut microbiota that are beneficial to gut health and new strategies and individual based therapeutic treatments for correcting dysbiosis occurring in different disease conditions. Constructive modulation of gut microbiota through potential therapeutics such as prebiotics, probiotics, antibiotics and faecal transplantation are a promising clinical target for many diseases including obesity, diabetes, cardiovascular disease, inflammatory bowel disease, allergy and protective immunity against infections. Many national and international projects and companies are focussed on studying the microbial communities and the specific roles they play in human health and diseases. 


\section{Introduction}

The gastrointestinal tract of human is a unique ecosystem of many microbes residing in a gut which greatly influence the metabolism and health of the host. Gut microbiota regulates the host immune responses. (1) A complex relationship occurs between the gut microbiome and its host, and starting from the birth many factors play role in shaping the composition and alterations in gut microbiome of the host. (2). More than 50 bacterial phyla have been described, but the human gut microbiota is specifically dominated by two of them i.e. Bacteroidetes and Firmicutes while Actinobacteria, Cyanobacteria, Fusobacteria, Proteobacteria and Verrucomicrobia are present in minor amounts. (3) Role of indigenous gut microbiome in health and nutrition can be understood by various researches on diverse human population. (4)

Recently the interest in gut microbiota mainly the bacterial community has been increased, as to see how crucial these microbes play role in regulating appropriate immune function and wellbeing and susceptibility to inflammatory and infectious diseases. (5) It has been found that gut microbiota has a major function of balancing the homeostasis by regulating of metabolic pathways, nutrient metabolism and production of vitamins. (6) It has been suggested through many researches that dysbiosis in the gut microflora occurs in various disease conditions such as obesity and diabetes. (7) In recent years the change in lifestyle and influence of western culture has led to higher incidence of metabolic diseases such as obesity, coronary heart diseases, diabetes etc. Beside these India is still facing a problem of higher percent of under nourishment. Changes in gut microflora have been found to be an important factor for the occurrence of all these diseases (8).

\section{Development of gut microbiome}

Microbes are present at various sites in human body and act specifically to the targeted sites, of these sites gastrointestinal tract is most densely populated. The human gut consists micro-eukaryotic, bacterial and viral populations. (9) At the time of birth colonization of microbiota occurs in the gut of the baby, and mother plays a role as a source of inoculum for these bacteria through birth canal and through breast milk.(10) The composition of gut microbiota undergo varied changes greatly until it get stabilized at the end of first year of life. (11)

The gut microbiota is found to reach an adult state at around 3 years of age. (12). After the colonization, the alteration and succession of gut microbiota depends upon many factors such as age, gender, geographical indication, diet, genetic composition and health status of the host.(13) Use of antibiotics, has also been recently recognized as one of the major cause which greatly disturbs the composition of the normal flora.

Major phyla present in the gut include Actinobacteria, Bacteroidetes, Firmicutes, Proteobacteria, Tenericutes and Verrucomicrobia. Out of which dominant phyla making up more than 90 percent of the total microbial population in both mice and humans are Bacteroidetes and Firmicutes. (14) Ley et al., has reported that there occurs two levels i.e. 'top-down' and 'bottom-up' selection on which the structure of microbial community is developed in the human gut. The top-down selection is dependent upon host driven factors that help distantly related microbial members to emerge and evolve convergently for functionally similar genes while bottom-up selection method helps microbes to perform specialize specific function within the gut (15). 


\section{Major function of gut microbiome in human body}

The relationship between gut microbiome and humans is "Symbiotic" in nature that is they live together for mutually benefiting each other. The gut microbiome plays an important role in homeostasis by controlling the metabolic pathways, nutrient metabolism, promoting production of vitamins and preventing colonization by pathogens (16). Beside these basic functions, it has also been reported that gut microbiota are essential in the development and maturation of mucosal and systemic immune responses and for maintaining the integrity of intestinal epithelial tissues barrier function (16). On the other hand "Dysbiosis" is the abnormal microbial colonization of the intestine, where a change in Quantity and Quality of micro flora occurs. With the disturbance in equilibrium of intestinal microflora, the optimal health effects are lost and it has been suggested through many studies that dysbiosis can significantly lead to pathological intestinal conditions such as obesity $(15,17)$ and malnutrition (18), systematic diseases such as diabetes (19) and chronic inflammatory diseases such as inflammatory bowel disease (IBD), encompassing ulcerative colitis (UC) and Crohn's disease (CD) (20).

As the volume of data relating to the composition and functional potential of the gut microbiota increases, the number of diseases that have been linked with alterations in our gut microbial community has also expanded. Many studies suggest the change in the ratio of Firmicutes / Bacteroidetes in various physiological conditions such as ageing and diabetes (21). The balance of beneficial and harmful effect of microbial population depends upon their composition, diversity, distribution and metabolic output as shown in Figure 1. (22).

\section{Role of gut microbiota in prevention of different diseases}

Comparison of diversity of microbial population between different individuals led to identify their association with different pathological conditions. Many such studies describe associations between presence/absence of a range of microbial species and the disease, and furthermore it helps to build hypothesis linking dysbiosis and the etiology of various pathological conditions (23).

\section{Irritable bowel syndrome}

Irritable bowel syndrome is a functional disorder characterized by symptoms such as abdominal discomfort or pain, bloating, flatulence and altered bowel habits. Though IBD is not a serious illness, but $10-15 \%$ of adult population get afflicted to the disorder which leads to higher economic burden and lowering the quality of life of infected people (24). Changes in the bowel habit is due to imbalance of autonomic system in the gut whereas the abdominal discomfort and pain are said to involve disturbance in the inter communication between the gut and the brain known as "gut-brain axis" (25). Changes in specific species of microbial diversity differ from study to study but some broad patterns are evolved. This includes the loss of community diversity, increasing the amount of Gammaproteobacteria, and on the other hand decreased relative abundance of several texas within the phylum Fermicutes (26). In addition to it, other species with decreased diversity in IBD includes Bacteroides fragilis, B. vulgatus, Ruminococcus albus, $R$. callidus, and $R$. bromii, which were found to be 5 times more in the healthy subjects than the patients with IBD (27). A high Firmicutes: Bacteroides ratio is found in some IBS patients and appears to correlate with depression and anxiety (28). 


\section{Obesity and metabolic diseases}

Obesity is a widely prevalent disease which gives rise to other metabolic abnormalities collectively called as metabolic syndrome. The indicators of these metabolic abnormalities are hyperglycemia, hyperlipidemia, insulin resistance, obesity and liver steatosis (29). Genetic susceptibility and environmental factors are thought to be the cause of development of obesity. Recently gut microbiota is being increasingly recognized as important factor that connects gene, environment and immune system (30). Increment in the ratio of Firmicutes to Bacteroidetes and reduction in the other bacterial diversity of the gut microbiota was found to be associated with both obesity and diet induced mouse models $(31,32)$. One such study conducted to analyze the association between gut microbiota and obesity in which transplantation of human fecal microbiota from obese $(\mathrm{Ob})$ and lean $(\mathrm{Ln})$ twins to germ free mice was done which showed that the gut microbiota modulates host metabolism to regulate body mass. Mice receiving fecal microbiota from the obese twins had found to have increased total and fat mass and increased susceptibility to obesity associated metabolic disorder, contrary to it such phenotypes were not found in mice recieveng fecal microbiota from lean twin(33). Altogether, the gut microbiota has substantial effect on metabolic disturbances by influencing the efficacy of energy harvest and storage, low-grade inflammation and browning of adipose tissues (34)

\section{Allergic diseases}

Allergic diseases are affecting about half of the population worldwide and therefore it is a global health concern. Most of the common allergic diseases prevalent are atopic eczema, food allergy, asthma and allergic rhino conjunctivitis (35). Beside Genetic and environmental factors, one of the major factors for development of allergic disease is found to be the dysbiosis of gut microbiota. In one such study conducted reduced gut microbial diversity in infants was found to be associated with increased allergic risk in school age children (36). Moreover, another recent study has shown that lower abundance of bacteria such as Akkermansia, Bifidobacterium and Faecalibacterium including higher concentration of particular fungi including a Candida and Rhodotorula may predispose to allergy susceptibility in neonates by influencing $\mathrm{T}$-cell differentiation (37). Various factors suggesting individual difference in microbial diversity and risk of developing allergic disease in infants are caesarean section, diet, antibiotic treatment, biodiversity in homes (mattresses, dust, etc.), in surrounding environment, and in family members (skin, mouth, and gut) (38).

The Canadian Healthy Infant Longitudinal Development (CHILD) Study reported a transient alteration in the population of gut microbiota during the first 100 days life period in infants at risk of asthma, which is found to be associated with reduced fecal acetate concentrations (39).

\section{Host immunity and homeostasis toward infectious diseases}

In the maintenance of optimum immune function gut microbiota plays an important role. In addition to it both gut microbiota and immune system are closely related to many physiological processes such as metabolism, behaviour, digestive, respiratory and nervous system (40). Manipulation in gut microbial community either through antibiotics or microbiota reconstitution provides key evidences for influential role of gut microbiota in maintaining the immune homeostasis (41). In a recent research, it was reported that optimum population of erythroid cells enriched in tha neonates plays a major role in maintenance of immunoregulatory 
environment and prevents mucosal inflammation following the colonization with the microbiota (42) in an another study conducted it was found that from fibre fermentation the gut microbiota produces short chain fatty acid such as propionate, butyrate etc. which keeps the gut healthy and also have a role as anti inflammatory (43).
Neutrophil plays a crucial role in the maintenance of innate immunity system and have a significant effect of microbiota in the regulation of Neutrophils has been found. A study found that impaired superoxide anion and nitric oxide generation was present in peripheral blood neutrophill of Germ Free rats with decreased phagocytic functions (44).

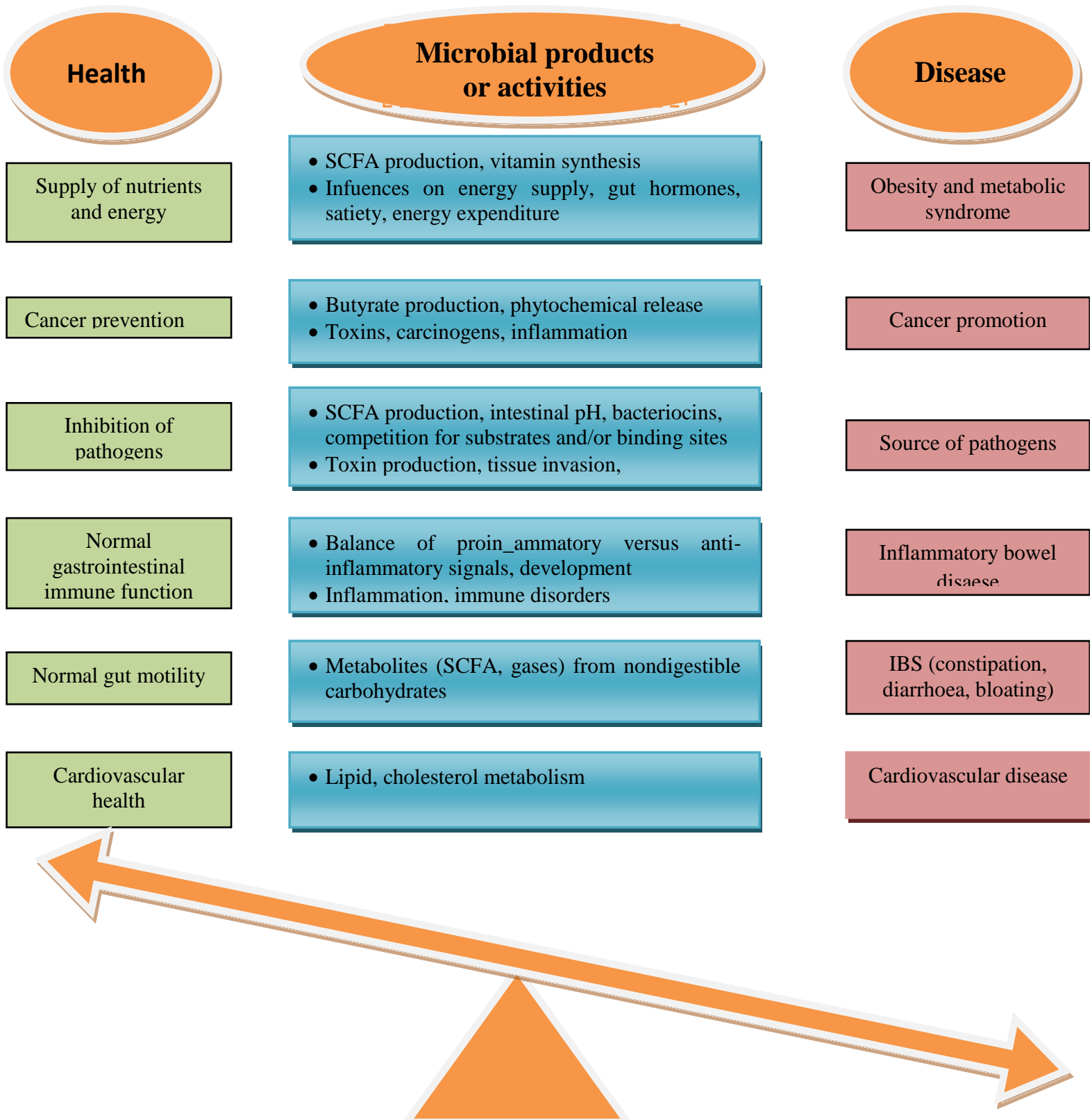

Figure.1 Effect of gut microbial community on healh. Most of the activities of microflora is shown in the middle column as a function of whole community rather than being specific to a single phyla. The balance of the community and its net metabolic output determines its beneficial and harmful effects on health as shown in right and left columns respectively 
Tabel.1 Effects of probiotics or carbohydrates with prebiotic properties in patients with overweight or metabolic disease (73)

\begin{tabular}{|c|c|c|c|c|c|}
\hline $\begin{array}{l}\text { Microbiota } \\
\text { Probiotics: }\end{array}$ & Study design & $n$ & Duration & Treatment & Results \\
\hline $\begin{array}{l}\text { Lactobacillus } \\
\text { acidophilus (68) }\end{array}$ & $\begin{array}{l}\text { Randomized, } \\
\text { double-blind } \\
\text { intervention }\end{array}$ & $\begin{array}{l}45 \text { individuals } \\
\text { with glucose } \\
\text { intolerance } \\
\text { and/or diabetes } \\
\text { mellitus }\end{array}$ & 4 weeks & $\begin{array}{lr}\text { Probiotic } & (1010 \\
\mathrm{CFU} / \text { day) } & \text { versus } \\
\mathrm{SiO}_{2} / \text { lactose (placebo) }\end{array}$ & $\begin{array}{l}\text { Systemic inflammation } \\
\text { upon LPS challenge in } \\
\text { both groups } \\
\text { Probiotics prevented loss } \\
\text { of insulin sensitivity } \\
\text { observed in the placebo } \\
\text { group }\end{array}$ \\
\hline Trebiotics: & $\begin{array}{l}\text { Randomized, } \\
\text { multicenter, } \\
\text { double-blind, } \\
\text { placebo-controlled } \\
\text { intervention }\end{array}$ & $\begin{array}{l}87 \text { individuals } \\
\text { with a BMI of } \\
24.2-37.0 \mathrm{~kg} / \mathrm{m} 2 \\
\text { and visceral } \\
\text { adiposity }\end{array}$ & 12 weeks & $\begin{array}{l}\text { Fermented milk with } \\
\text { probiotics }(1011 \\
\text { CFU/day) or without } \\
\text { probiotics (placebo) }\end{array}$ & $\begin{array}{l}\text { Reduced body weight, } \\
\text { BMI, waist and hip } \\
\text { circumference, visceral } \\
\text { and subcutaneous fat } \\
\text { mass in the probiotic } \\
\text { versus the placebo group }\end{array}$ \\
\hline Arabinoxylan (70) & $\begin{array}{l}\text { Randomized cross- } \\
\text { over intervention }\end{array}$ & $\begin{array}{l}15 \text { individuals } \\
\text { with type } 2 \\
\text { diabetes mellitus }\end{array}$ & 5 weeks & $\begin{array}{lr}\begin{array}{l}\text { Bread and } \\
\text { with }\end{array} & 14 \% \\
\text { arabinoxylan } & (0 \% \text { for } \\
\text { placebo) }\end{array}$ & $\begin{array}{l}\text { Reduced fasting } \\
\text { glycemia, post-OGTT } \\
\text { glycemia } \\
\text { insulinemia } \\
\text { No difference in blood } \\
\text { lipid level, fat mass and } \\
\text { blood pressure }\end{array}$ \\
\hline $\begin{array}{l}\text { Inulin-type } \\
\text { fructans(71) }\end{array}$ & $\begin{array}{l}\text { Randomized, } \\
\text { double-blind, } \\
\text { placebo-controlled } \\
\text { intervention }\end{array}$ & $\begin{array}{l}48 \quad \text { individuals } \\
\text { with overweight } \\
\text { or obesity }\end{array}$ & 12 week & $\begin{array}{l}21 \mathrm{~g} \text { per day } \\
\text { oligofructose } \\
\text { maltodextrin (placebo) }\end{array}$ & $\begin{array}{l}\text { Reduced body weight, } \\
\text { caloric intake, GIP } \\
\text { No difference in fasting } \\
\text { glucose, insulin, ghrelin, } \\
\text { GLP-1, PYY and leptin } \\
\text { levels } \\
\text { After MTT: reduced } \\
\text { glycemia, insulin, } \\
\text { AUCfor ghrelin, AUC } \\
\text { for PYY, AUC for leptin, } \\
\text { but no difference in GIP } \\
\text { level or AUC for GLP-1 }\end{array}$ \\
\hline $\begin{array}{l}\text { Inulin-type } \\
\text { fructans (72) }\end{array}$ & $\begin{array}{l}\text { Randomized, } \\
\text { double-blind, } \\
\text { cross-over } \\
\text { intervention }\end{array}$ & $\begin{array}{l}7 \quad \text { overweight } \\
\text { patients with } \\
\text { nonalcoholic } \\
\text { steatohepatitis }\end{array}$ & 8 weeks & $\begin{array}{lr}16 \quad \mathrm{~g} \text { per } & \text { day } \\
\text { oligofructose } & \text { or } \\
\text { maltodextrine } & \\
\text { (placebo) } & \end{array}$ & $\begin{array}{l}\text { Reduced aspartate } \\
\text { aminotransferase and } \\
\text { fasting insulin levels } \\
\text { No difference in levels of } \\
\text { triglycerides, fasting } \\
\text { glucose and cholesterol }\end{array}$ \\
\hline
\end{tabular}


The diversity of gut microbiota is greatly affected by the dietary habit. It is demonstrated in a study using Germ free mice with fecal transplantation of human gut microbiota, that moving from low fat, plant polysaccharide rich diet to a high fat, high sugar diet can alter the population of microbiome in one day. This diet alteration showed the risk of developing metabolic diseases and increased susceptibility to infection consequently lowering the immunity (45).

\section{Diet and gut microbiota}

Dietary habits can have a great impact on gut environment affecting gut transit time and $\mathrm{pH}$ and thus affecting the composition of the microbiota. The human intestine does not contain enzymes needed to degrade the structural polysaccharides present in the plant material, and thus it is fermented through colonic bacteria for efficient degradation. The form of carbohydrate available to the microbiota is resistant starch, non starch polysaccharide and oligosaccharide (46). Fermentation of complex polysachharide inthe colon by colonic bacteria results in production of short chain fatty acids (SCFA) such as acetate, propionate and butyrate in a ratio of 3:1:1(47). Some of the observational studies have repoted the faecal microbiota difference in Vegetarian and omnivores. The study found that the fecal microbiota of omnivores have an abundance of Clostridium cluster $(48,49)$. In another such study a western diet containing high sugar and high fat was found to be associated with decrease in gut microbial diversity, ot the other part an agrarian diet rich in fruits and vegetables with high fiber content was associated with increased bacterial gene richness(50). Several studies have been conducted to investigate the influence of whole grain breakfast on gut microbiota composition. In one such study it was reported that consumption of maize- based whole grain breakfast cereal for 3 weeks increased the level of Bifidobacterium in faeces. Moreover, ratio of Lactobacillus/Enterococcus was also increased (51). After the consumption of red berries increase in Bifidobacterium genus was also reported (52). Beside these effects of consumption of almond, chickpea and soyabean on gut microbiota has been studied and found to be positively correlated (53-55). But there is limited data available as to access the effect of fruits, vegetables, nuts and legumes consumption on the composition of gut microbiota.

\section{Potential therapies for the modulation of the gut microbiota to maintain health}

\section{Probiotics}

World health organization (WHO) and food and agriculture organization (FAO) defined probiotics as 'living microorganisms, which when administered in adequate amounts confer health benefits on the host' (56). Nobel laureate Elie Metchnikoff showed the longetivity of Bulgarians with the consumption of viable Lactobacilli containing, milk products which suggested that the ingestion of certain microbes could be beneficial for health (57). Consumption of probiotics can be preventative measure in maintaining the healthy and optimum gut microflora. Probiotics has been recognized as a therapeutic approach to maintain health and prevent many diseases such as to modulate immunity, treat athereosclerosis and arteriosclerosis, cancer, Helicobacter pylori infections, improve lactose intolerance, and prevent or reduce the effects of atopic dermatitis, treat, diarrhoea, and constipation, candidiasis, urinary tract infections etc (58).Currently probiotics are widely marketed as supplementary and functional food such as cheese, ice-cream, yogurt, chocolates as well as non dairy food products (59). Probiotic 
plays its role $\mathrm{i}$ a body by manipulation of intestinal microbial communities, suppression of pathogens, stimulation of epithelial cell proliferation and differentiation and fortification of the intestinal barrier (60). Mainly lactic acid producing Lactobacillus and Bifidobacteria species are classified under probiotics but it was reported that not all the probiotics are beneficial in all the circumstances. Therefore, a careful selection of specific organism for obtaining the desired clinical outcome is said to be an effective strategy for the treatment of an ailment (61).

\section{Prebiotics}

Food and agricultural organization (FAO) has defined the prebiotics as 'non-viable food component that confers a health benefit on the host associated with modulation of the microbiota' (62). The most of the studied prebiotics till now are Inulin, fructooligosaccharides (FOS) and oligofructose. Beside these the other important prebiotics found are oligosaccharides, such as xylooligosaccharides (XOS), pecticoligosaccharides (POS), cyclodextrins, palatinose and OS from pullulan (63). An arabinxylan is a hemicellulose that is located in a cell wall of plants and has a structural role. It is found in both soluble and insoluble dietary fiber whereas fructans are found only in soluble dietary fibers (64). The prebiotics are reported to reduce constipation, foster weight gain or loss, maintains blood glucose and lipids level and act a anticarcinogenic agent (65). Prebiotics induces a selective stimulation of the host's own beneficial microbiota, as prebiotic is substrate that is selectively fermented, stimulates the growth and activity of the microorganism that are of interest and thus leads to desired health effect (66). Prebiotic can be included in a diet by the consumption of Dietary fiber such as pectin (present in apple, strawberries), hemicellulose (present in whole grains, leafy vegetables, carrot etc) and oligosacaccharides. Protective mechanism of prebiotics involves modulation of gut microbiota, induction of enteroendocrine L cell proliferation, alteration in secretion of gut peptides and changes in inflammatory response (67).

\section{Faecal microbiota transplantation (FMT)}

In the recent years faecal microbiota transplantation has made an immense progression and has been evolved as an effective therapeutic for management of many diseases (74). Faecal microbiota transplantation is a method in which the solution prepared from the faecal material of donor is administered directly to the intestine of recipient in order to change directly the microbial diversity of recipient and induces the health benefit (75). FMT is found to be not a new concept and it has been used 2000 years ago by Ge Hong in china to treat severe diarrhoea and food poisoning (76). FMT was found to be superior to antibiotic treatment in treating antibiotic associated recurrent Clostridium difficile infections (CDIs) (77). Recently number of randomised trials has reported the beneficial effect of FMT in the treatment of inflammatory bowel disease, Obesity and other metabolic diseases. In a randomised controlled trial conducted 75 patients with active UC were included and there were randomized with weekly FMT or water enema for the period of 6 weeks, and found the remission in $24 \%$ of patients treated with FMT and 5\% treated with water as control (78). Another study shows that microbiota has role to play in management of obesity and other metabolic disorders. The study found that the colonization of germ free mice with faecal microbiota of obese resulted in increased adiposity as compared to one that was transplanted with lean microbiota (79). As far as safety is concerned of FMT, it has been found that few subjects enrolled in a study have experienced the mild symptoms of 
dizziness, diarrhoea or fever (80). Many efforts are underway to analyze the association of gut microbiota in the pathophysiology of many other conditions, such as liver disease, colorectal cancer, oesophageal and gastric adenocarcinoma and autism (81).

It is concluded in the recent years our knowledge about relationship between the gut microbiota and health has been furnished with consortium of the Human Microbiome Project and Metagenomics of the human intestinal tract (MetaHit). Beside this in India Pune microbiome project and recently launched the Indian human microbiome projects are also moving into the direction. The gut microbiota diversity and their by products greatly influences our metabolism, weight, health and immunity. Much of role of overall microbiota and health has been established by many researches. It is found that manipulation of gut flora may be an integral part of weight loss programs and different disease treatments. Regular consumption of probiotic, prebiotic and symbiotic is also an effective alternate to maintain healthy gut microbiota. Future studies must focus on the mechanisms of influence of specific species of microbiota in different states of health so that individual therapeutic treatment can be done.

\section{References}

1. Andreasen, A. S. et al., (2010). Effects of Lactobacillus acidophilus NCFM on insulin sensitivity and the systemic inflammatory response in human subjects. Br. J. Nutr. 104, 1831-1838

2. Arrieta MC, Stiemsma LT, Dimitriu PA, Thorson L, Russell S, YuristDoutsch S et al., (2015) Early infancy microbial and metabolic alterations affect risk of childhood asthma. Sci Transl Med; 7: 307ra152.

3. Binns N. (2013) Probiotics, Prebiotics and the Gut Microbiota.. ILSI Europe. Pp: 14-16.

4. Bisgaard H, Li N, Bonnelykke K, Chawes BL, Skov T, Paludan-Muller $\mathrm{G}$ et al., (2011) Reduced diversity of the intestinal microbiota during infancy is associated with increased risk of allergic disease at school age. $\mathrm{J}$ Allergy Clin Immunol; 128: 646-652 e641-645.

5. C De Filippo, D Cavalieri, M Di Paola, M Ramazzotti, J B Poullet, S Massart, S Collini, G Pieraccini and P Lionetti (2010) Impact of diet in shaping gut microbiota revealed by a comparative study in children from Europe and rural Africa. PNAS 107:14691-14696.

6. Carvalho-Wells AL, Helmolz K, Nodet C, Molzer C, Leonard,C, McKevith B, et al., (2010) Determination of the in vivo prebiotic potential of a maize-based whole grain breakfast cereal: a human feeding study. Br J Nutr; 104: 1353-6.

7. Catherine S, Gardiner G, Meehan H, Collins K, Fitzgerald G, Lynch P B, et al., (2001) Market potential for probiotics. Am J Clin Nutr; 73 (suppl), 476-83.

8. Clarke T B, Davis K M, Lysenko E S, Zhou A Y, Yu Y, Weiser J N (2010) Recognition of peptidoglycan from the microbiota by Nod1 enhances systemic innate immunity. Nat Med; 16:228-31; $\quad$ PMID:20081863; http://dx.doi.org/10.1038/nm.2087

9. Daubioul, C. A., Horsmans, Y., Lambert, P., Danse, E. and Delzenne, N. M. (2005). Effects of oligofructose on glucose and lipid metabolism in patients with nonalcoholic steatohepatitis: results of a pilot study. Eur. J. Clin. Nutr. 59, 723-726

10. De Filippo C, Cavalieri D, Di Paola M, et al., (2010) Impact of diet in 
shaping gut microbiota revealed by a comparative study in children from Europe and rural Africa. Proc Natl Acad Sci U S A; 107: 14691-14696.

11. Distrutti E, Salvioli B, Azpiroz F, Malagelada J R (2004) Rectal function and bowel habit in irritable bowel syndrome. Am J Gastroenterol; 99: 131-137 (PMID: 14687154).

12. Doré J, Blottière H. (2015) The influence of diet on the gut microbiota and its consequences for health. Curr Opin Biotechnol 32: 195-9.

13. Druart C, Alligier M, Salazar N, Neyrinck A M, Delzenne N M. Modulation of the gut microbiota by nutrients with prebiotic and probiotic properties. Review. Adv Nutr. 2014; 5: S624-S633.

14. Eckburg P B, Bik E M, Bernstein C N, Purdom E, Dethlefsen L, Sargent M, Gill S R, Nelson K E, Relman D A (2005) Diversity of the human intestinal microbial flora. Science 308:1635-38.

15. Elahi S, Ertelt J M, Kinder J M, Jiang T T, Zhang X, Xin L, Chaturvedi V, Strong B S, Qualls J E, Steinbrecher K A, et al., (2013) Immunosuppressive CD71+ erythroid cells compromise neonatal host defence against infection. Nature. 504:158-162. (PubMed: 24196717)

16. Fernandez-Raudales D, Hoeflinger $\mathbf{J}$ L, Bringe N A, Cox S B, Dowd S E, Miller M J, et al., (2012) Consumption of different soymilk formulations differentially affects the gut microbiomes of overweight and obese men. Gut Microbes; 3: 490_500.

17. Fernando W M, Hill J E, Zello G A, Tyler R T, Dahl W J, Van Kessel A G. (2010) Diets supplemented with chickpea or its main oligosaccharide component raffinose modify faecal microbial composition in healthy adults. Benef Microbes; 1: 197_207.

18. Flint H J, Scott K P, Louis P and Duncan S H (2012) The role of the gut microbiota in nutrition and health. Nat. Rev. Gastroenterol. Hepatol. 4: 1-13.

19. Food and Agriculture Organization (2008). FAO Technical Meeting on Prebiotics. Rome, Italy: FAO. pp. 112.

20. Frank, D., St Amand, A., Feldman, R., Boedeker, E., Harpaz, N. and Pace, N. (2007) Molecular-phylogenetic characterization of microbial community imbalances in human inflammatory bowel diseases. Proc Natl Acad Sci USA 104: 1378013785.

21. Fujimura K E, Sitarik A R, Havstad S, Lin D L, Levan S, Fadrosh D et al., (2016) Neonatal gut microbiota associates with childhood multisensitized atopy and $\mathrm{T}$ cell differentiation. Nat Med; 22: 11871191.

22. Furet, J. P., Kong, L. C., Tap, J., Poitou, C., Basdevant, A., and Bouillot, J. L. (2010). Differential adaptation of human gut microbiota to bariatric surgery-induced weight loss: Links with metabolic and low-grade inflammation markers. Diabetes, 59, 3049-3057.

23. Graf D, Di Cagno R, Fak F, Flint H J, Nyman M, Saarela M and Watz B. (2015) Contribution of diet to the composition of the human gut microbiota. Microbial Ecology in Health \& Disease 26: 1-11.

24. Gupta S, Allen-Vercoe E and Petrof E O. (2016) Fecal microbiota transplantation: in perspective Ther Adv Gastroenterol, Vol. 9(2) 229-239.

25. Jeffery IB, O'Toole PW, Öhman L, Claesson MJ, Deane J, Quigley EM, Simrén M. (2012) An irritable bowel syndrome subtype defined by species- 
specific alterations in faecal microbiota. Gut; 61: 997-1006 (PMID: 22180058 DOI: 10.1136/gutjnl-2011301501).

26. Joint FAO/WHO (2006) Working Group on Drafting Guidelines for the Evaluation of Probiotics. Rome.

27. Kabeerdoss J, Devi R S, Mary R R, Ramakrishna B S. (2012) Faecal microbiota composition in vegetarians: comparison with omnivores in a cohort of young women in southern India. Br J Nutr 108: 953_7.

28. Kadooka, Y. et al., (2010). Regulation of abdominal adiposity by probiotics (Lactobacillus gasseri SBT2055) in adults with obese tendencies in a randomized controlled trial. Eur. J. Clin. Nutr. 64, 636-643

29. Kang S, Denman SE, Morrison M, Yu Z, Dore J, Leclerc M et al., (2010) Dysbiosis of fecal microbiota in Crohn's disease patients as revealed by a custom phylogenetic microarray. Inflamm Bowel Dis 16: 2034-42.

30. Karlsson F H, Tremaroli V, Nookaew I, Bergström G, Behre C J, Fagerberg B, Nielsen J, Bäckhed F (2013) Gut metagenome in European women with normal, impaired and diabetic glucose control. Nature 498: 99-103.

31. Kau, A., Ahern, P., Griffin, N., Goodman, A. and Gordon, J. (2011) Human nutrition, the gut microbiome and the immune system. Nature 474: 327-336.

32. Kelly C R, Ihunnah C, Fischer M, Khoruts A, Surawicz C, Afzali A, et al., (2014) Fecal microbiota transplant for treatment of Clostridium difficile infection in immunocompromised patients. Am J Gastroenterol; 109(7):1065-71.

33. Kumar M, Kumar R, Poovai P D, Kalaichelvan P T (2012) Probiotics and multitude of health benefits. J Res Bio; 2: 102-13.

34. Larsen N, Vogensen FK, van den Berg FWJ, Nielsen DS, Andreasen AS et al., (2010) Gut Microbiota in Human Adults with Type 2 Diabetes Differs from Non-Diabetic Adults. PLoS One 5(2):e9085.

35. Lee B J and Bak Y T (2011) Irritable Bowel Syndrome, Gut Microbiota and Probiotics J Neurogastroenterol Motil, 17(3): 252-266.

36. Ley RE, Peterson DA, Gordon JI (2006) Ecological and evolutionary forces shaping microbial diversity in the human intestine. Cell 124: 837848.

37. Lieke WJ van den Elsen, Hazel C Poyntz, Laura S Weyrich, Wayne Young and Elizabeth E Forbes-Blom (2017) Embracing the gut microbiota: the new frontier for inflammatory and infectious diseases. Clinical \& Translational Immunology 6, e125; doi:10.1038/cti.2016.91

38. Liu Z, Lin X, Huang G, Zhang W, Rao P, Ni L. (2014) Prebiotic effects of almonds and almond skins on intestinal microbiota in healthy adult humans. Anaerobe; 26: 1_6.

39. Longo G, Berti I, Burks AW, Krauss B, Barbi E. (2013) IgE-mediated food allergy in children. Lancet; 382:165664.

40. Lu, Z. X., Walker, K. Z., Muir, J. G. and O'Dea, K. (2004). Arabinoxylan fibre improves metabolic control in people with type II diabetes. Eur. J. Clin. Nutr. 58, 621-628

41. Mariño E (2016) The gut microbiota and immune-regulation: the fate of health and disease. Clinical \& Translational Immunology 5, e107; doi:10.1038/cti.2016.61

42. Matamoros S, Gras-Leguen C, Le Vacon F, Potel G, de La Cochetiere M 
F (2013) Development of intestinal microbiota in infants and its impact on health. Trends Microbiol 21: 167-73.

43. Mathur P, Shah B (2011) Research priorities for prevention and control of on communicable diseases in India. Indian J Community Med 36: S72S77.

44. Matijasic B B, Obermajer T, Lipoglavsek L, Grabnar I, Avgustin G, Rogelj I. (2014) Association of dietary type with fecal microbiota in vegetarians and omnivores in Slovenia. Eur J Nutr; 53: 1051_64.

45. Metchnikoff, E. and Mitchell, P. (1907) The Prolongation of Life: Optimistic Studies. London: W. Heinemann/New York: G.P. Putnam's Sons.

46. Mileti E, Matteoli G, Iliev I D, Rescigno M. (2009) Comparison of the immunomodulatory properties of three probiotic strains of Lactobacilli using complex culture systems: prediction for in vivo efficacy. PLoS ONE.; 4:e7056. (PubMed: 19756155)

47. Mitsou EK, Kirtzalidou E, Oikonomou I, Liosis G, Kyriacou A (2008) Fecal microflora of Greek healthy neonates. Anaerobe 14:94101.

48. Moayyedi, P., Surette, M., Kim, P., Libertucci, J., Wolfe, M., Onischi, C. et al., (2015) Fecal microbiota transplantation induces remission in patients with active ulcerative colitis in a randomized, controlled trial. Gastroenterology 149: 102-109.

49. Morgan XC, Tickle TL, Sokol H, Gevers D, Devaney KL, Ward DV et al., (2012) Dysfunction of the intestinal microbiome in inflammatory bowel disease and treatment. Genome Biol 13: R79.

50. Musso G, Gambino R and Cassader M. (2010) Obesity, Diabetes, and Gut
Microbiota. Diabetes Care 33:22772284.

51. Nathalie M. Delzenne, Audrey M. Neyrinck, Fredrik Bäckhed and Patrice D. Cani (2011). Targeting gut microbiota in obesity: effects of prebiotics and probiotics Nat. Rev. Endocrinol. 7, 639-646

52. Neish A.S, Denning T L (2010) Advances in understanding the interaction between the gut microbiota and adaptive mucosal immune responses. F1000 Biology Reports $2: 27$

53. Palmer C, Bik E M, DiGiulio D B, Relman D A, Brown P O (2007) Development of the human infant intestinal microbiota. PLoS Biol 5:e177.

54. Parnell, J. A. and Reimer, R. A. (2009). Weight loss during oligofructose supplementation is associated with decreased ghrelin and increased peptide YY in overweight and obese adults. Am. J. Clin. Nutr. 89, 1751-1759

55. Qin, J., Li, R., Raes, J., Arumugam, M., Burgdorf, K., Manichanh, C. et al., (2010) A human gut microbial gene catalogue established by metagenomic sequencing. Nature 464: 59-65.

56. Queipo-Ortuno MI, Boto-Ordonez M, Murri M, Gomez- Zumaquero JM, Clemente-Postigo M, Estruch R, et al., (2012) Influence of red wine polyphenols and ethanol on the gut microbiota ecology and biochemical biomarkers. Am J Clin Nutr; 95: 1323_34.

57. R E Ley, F Bäckhed, P Turnbaugh, C A Lozupone, R D Knight and J I Gordon (2005) Obesity alters gut microbial ecology. Proc Natl Acad Sci USA. 102: 11070-11075.

58. Raninen K, Lappi J, Mykkänen H, 
Poutanen K. (2011) Dietary fiber type reflects physiological functionality: comparison of grain fiber, inulin, and polydextrose. Nutr Rev. 69:9-21.

59. Ray K. 2(015) Gut microbiota: the gut virome and bacterial microbiome-the early years Nat Rev Gastroenterol Hepatol. 12: 609- 11.

60. Richards J L, Yap Y A, McLeod K H, Mackay C R, Mariño E. (2016) Dietary metabolites and the gut microbiota: an alternative approach to control inflammatory and autoimmune diseases. Clin Trans Immunol; 5: e82.

61. Ridaura VK, Faith JJ, Rey FE, Cheng J, Duncan AE, Kau AL, et al., (2013) Gutmicrobiota from twins discordant for obesity modulate metabolism in mice. Science. 341(6150): 1241214. doi: $10.1126 /$ science.1241214.

62. Rurangwa E, Laranja J L, Van Houdt R, Delaedt Y, Geraylou Z, Van de Wiele T, Van Loo J, Van Craeyveld V, Courtin CM, Delcour JA, et al., (2009) Selected nondigestible carbohydrates and prebiotics support the growth of probiotic fish bacteria mono-cultures in vitro. J Appl Microbiol., 106(3): 932-40.

63. Sekirov I, Russell S L, Antunes L C and Finlay B B (2010) Gut microbiota in health and disease. Physiol Rev 90: 859-904.

64. Sekirov I, Russell SL, Antunes LC, Finlay BB (2010) Gut microbiota in health and disease. Physiol Rev 90: 859-904.

65. Shetty S A, Marathe N P and Shouche Y (2013) Opportunities and challenges for gut microbiome studies in the Indian population. Microbiome 1:24.

66. Smits, L., Bouter, K., De Vos, W., Borody, T. And Nieuwdorp, M. (2013) Therapeutic potential of fecal microbiota transplantation. Gastroenterology 145: 946-953.
67. Thomas J. Borody, Lawrence J. Brandt, and Sudarshan Paramsothy. (2014) Therapeutic faecal microbiota transplantation: current status and future developments. Curr Opin Gastroenterol 30:97-105.

68. Thomas R. Abrahamsson, Richard You $\mathrm{Wu}$ and Maria C. Jenmalm. (2015) Gut microbiota and allergy: the importance of the pregnancy period. Pediatric Research, 77(1): 214-219.

69. Thomas, C. and Versalovic, J. (2010) Probiotics-host communication: modulation of signaling pathways in the intestine. Gut Microbes 1: 148163.

70. Topping D L, Clifton P M (2001) Short-chain fatty acids and human colonic function: 592 roles of resistant starch and nonstarch polysaccharides. Physiological Reviews 593;81:103164.

71. Turnbaugh PJ, Bäckhed F, Fulton L, Gordon JI. (2008) Diet-induced obesity is linked to marked but reversible alterations in the mouse distal gut microbiome. Cell Host Microbe; 3: 213-223.

72. Turnbaugh PJ, Ley RE, Mahowald MA, Magrini V, Mardis ER, Gordon JI. (2006) An obesity associated gut microbiome with increased capacity for energy harvest. Nature; 444: 10271131.

73. Turnbaugh PJ, Ridaura VK, Faith JJ, Rey FE, Knight R, Gordon JI. (2009) The effect of diet on the human gut microbiome: a metagenomic analysis in humanized gnotobiotic mice. Sci Transl Med; 1:6ra14; PMID: 20368178; http://dx.doi.org/10.1126/ scitranslmed.3000322

74. Turnbaugh, P., Ley, R., Mahowald, M., Magrini, V., Mardis, E. and Gordon, J. (2006) An obesity associated gut microbiome with 
increased capacity for energy harvest. Nature 444: 1027-1031.

75. van den Elsen L W J, Poyntz H C, Weyrich L S, Young W and ForbesBlom E (2017) Embracing the gut microbiota: the new frontier for inflammatory and infectious diseases. Clinical \& Translational Immunology 6: e125; doi:10.1038/cti.2016.91.

76. van Nood E, Vrieze A, Nieuwdorp M, Fuentes S, Zoetendal EG, de Vos WM et al., Duodenal infusion of donor feces for recurrent Clostridium difficile. N Engl J Med 2013; 368: 407-415.

77. Vijay-Kumar M, Aitken JD, Carvalho FA, Cullender TC, Mwangi S, Srinivasan S et al., (2010) Metabolic syndrome and altered gut microbiota in mice lacking toll-like receptor 5 . Science; 328: 228-231

78. Wu H J and Wu E (2012) The role of gut microbiota in immune homeostasis and autoimmunity Gut Microbes 3:1, 4-14.

79. Yatsunenko T, Rey F E, Manary M J, Trehan I, Dominguez-Bello M G, Contreras M, Magris M, Hidalgo G, Baldassano R N, Anokhin A P, Heath A C, Warner B, Reeder J, Kuczynski J, Caporaso J G, Lozupone C A, Lauber C, Clemente J C, Knights D, Knight R, Gordon J I (2012) Human gut microbiome viewed across age and geography. Nature 486:222-27.

80. Zhang F, Luo W, Shi Y, et al., Should we standardize the 1,700-yearold fecal microbiota transplantation? Am J Gastroenterol 2012; 107: 1755.

81. Zhang, H., DiBaise, J., Zuccolo, A., Kudrna, D., Braidotti, M., Yu, Y. et al., (2009) Human gut microbiota in obesity and after gastric bypass. Proc Natl Acad Sci USA 106: 2365-2370.

\section{How to cite this article:}

Poonam Jethwani and Kiran Grover. 2019. Gut Microbiota in Health and Diseases - A Review. Int.J.Curr.Microbiol.App.Sci. 8(08): 1586-1599. doi: https://doi.org/10.20546/ijcmas.2019.808.187 